\title{
Intermediate veins in swine (Sus scrofa domestica) kidney: authors' own anatomical classification
}

\author{
J. Szymański ${ }^{1}$, M. Polguj², M. Topol ${ }^{1}$, P. Oszukowski ${ }^{3}$ \\ ${ }^{1}$ Department of Normal and Clinical Anatomy, Interfaculty Chair of Anatomy and Histology, Medical University of Lodz, Poland \\ 2Department of Angiology, Interfaculty Chair of Anatomy and Histology, Medical University of Lodz, Poland \\ ${ }^{3}$ Department of Clinical Morphology, Chair of Anatomy, Medical University of Lodz, Poland
}

[Received 25 September 2014; Accepted 20 October 2014]

\begin{abstract}
Background: The use of domestic swine as an experimental animal is increasing steadily. Swine organs are the best animal model for urological experiments. The aim of the study was to evaluate the course and size of intermediate veins in a swine kidney. The research results were compared with the results obtained from studies on venous vascularisation of human kidneys. The knowledge of the above-mentioned vessels is important both in human and veterinary medicine and will enable researchers to compare and notice differences between human and swine organs.
\end{abstract}

Materials and methods: The study was conducted on 94 kidneys, 47 right ones and 47 left ones, taken from adult domestic swines (Sus scrofa domestica). The kidneys were prepared and corrosion casts were made.

Results: The average lumen diameter of secondary intermediate veins was $7.96 \mathrm{~mm}$. The average diameter of the primary intermediate veins directly inserted in the renal vein (type $A$ ) and primary intermediate veins inserted in the secondary intermediate veins (type $B$ ) amounted to $6.7 \mathrm{~mm}$ and $4.75 \mathrm{~mm}$, respectively. The average length of primary intermediate veins of type A was $21.91 \mathrm{~mm}$. Secondary intermediate veins were shorter - on average $19.83 \mathrm{~mm}$. Primary intermediate veins of type $B$ were on average $12.91 \mathrm{~mm}$ long.

Conclusions: Intermediate veins are formed in the area of vascular anastomoses on the level of renal papillae. The following veins can be distinguished: primary intermediate veins of type $A$ and type $B$, as well as secondary intermediate veins. Secondary intermediate veins and primary intermediate veins of type A run only on the ventral side of the renal pelvis. Only the primary intermediate veins of type $B$ can run on the dorsal side. From the anatomy point of view, intermediate veins of swine kidneys are very similar to equivalent vessels in human kidneys as regards their run and anastomoses. (Folia Morphol 2015; 74, 2: 229-235)

Key words: animal organs, renal structures, vessels, animal model, pig, swine

\section{INTRODUCTION}

The use of domestic swine as an experimental animal is increasing $[3,6,9]$. The internal organs of a swine (mainly heart and kidneys) are similar to human organs in terms of size and structure. Moreover, the species quickly achieves sexual maturity, has

Address for correspondence: Dr J. Szymański, Department of Normal and Clinical Anatomy, Medical University of Lodz, ul. Narutowicza 60, 90-136 Łódź, Poland, tel: +48 4263049 49, e-mail: jacek.szymanski1@umed.lodz.pl 
a short reproduction period and is easy to breed. Thus, these organs can be easily obtained. Some authors point out physiological similarities between the two species $[10,19]$.

Since the first laparoscopic nephrectomy in a swine, and straight after the first procedure of this type performed in a human, swine organs have been the best animal model used in urological experiments [11]. Newly introduced and improved surgical techniques and their role can be tested on animal models before they are implemented in a human $[1,19]$. Besides, swine organs can be used as models in education, training and renal surgeries. Using swine kidneys for educational purposes can enable surgeons to gain invaluable experience to perform operations on human kidneys. Students can gain experience starting with more simple techniques before they proceed to carry out more advanced procedures [2]. Animal organs which serve as anatomical models are very useful. Thus, it is necessary to know their features, which are both similar and different from human ones.

The swine is seriously considered in research on xenotransplantation [21], i.e. transplanting animal organs to human recipients. This animal species cannot be organ donors yet. However, the rapid development of xenotransplantation can 1 day result in saving human lives.

The aim of the study was to evaluate the course and size of intrarenal veins in swine. The knowledge of these is highly important both in human and veterinary medicine. The veins of swine have not been thoroughly examined. There are very few publications on the structure, course and anastomoses of veins or, if such publications exist, they are not detailed.

A study was made on the structure of vessels in swine and the results were compared with the results obtained from studies on venous vascularisation of human kidneys.

The knowledge of veins' course in a swine and venous vascularisation of human kidneys will enable researchers to compare these organs and notice differences in human and swine organs.

\section{MATERIALS AND METHODS}

The study was conducted on 94 kidneys, 47 right ones and 47 left ones taken from adult domestic swines (Sus scrofa domestica), of Great Polish White breed, of both sexes. The kidneys and surrounding structures were obtained directly after the animals had been slaughtered. The organ donors weighed $70-110 \mathrm{~kg}$ and aged from 12 to 18 months. Because the organs were taken after the commercial slaughtering, the permission of bioethical committee is not needed.

While carrying out the research, the kidneys were dissected and the corrosion casts were made. After the renal vein isolation, a cannula (size $1.2 \times 80$ ) was inserted into the lumen of the vein. The renal venous system was rinsed with distilled water. After draining with water, through the cannula, the chemohardenable coloured in blue material Plastogen $\mathrm{G}^{\circledR}$ (Alfons Schmidt, Germany) was injected into the ligated renal vein. The procedure performed under pressure made it easy to fill all the veins properly. Before injecting, Plastogen $\mathrm{G}^{\circledR}$ was diluted with methacrylate diluent so as to obtain consistence, which would penetrate all structures. In order to make the parts of venous vascularisation more visible, Plastogen $\mathrm{G}^{\circledR}$ was stained blue with pigment for acrylic paint. After filling the vein with the material, the renal vein stump was ligated and organ was immersed in $0.9 \%$ sodium chloride, in temperature $40^{\circ} \mathrm{C}$, for $24 \mathrm{~h}$ to allow Plastogen $\mathrm{G}^{\circledR}$ hardening. Next, the organs were corroded in $10 \%$ potassium hydroxide in a laboratory incubator. In this way, corrosion casts were obtained, which were then rinsed with tap water. After drying them, some measurements were made with a digital slide-calliper to an accuracy of $0.01 \mathrm{~mm}$. Photographs were taken with a digital camera (Canon EOS D50, Japan).

\section{RESULTS}

In the renal sinus, the interlobar veins ( $v v$. interlobares) are parts of venous plexuses, from which start from 2 to 8 vessels. They are primary intermediate veins (IVs), which are an extension of interlobar veins. Before they join and become the renal vein they often join and form secondary IVs, i.e. vessels of a bigger diameter. For the purpose of this research, primary IVs have been divided into two types; type A includes primary IVs, which are directly inserted in the renal vein and type $B$ includes primary IVs, which are inserted in the secondary IVs (Figs. 1-3). Primary IVs are different in size from secondary IVs. The fact is thoroughly described further in the article.

A secondary IV is formed as a result of joining at least two primary IVs of type $B$, and therefore, it is dependent on their presence. Thus, there is always more than one primary IV of type $B$. The number of primary IVs inserted in secondary IVs (type B) ranges $0-8$ vessels in 1 kidney. However, in as many as 46 exa- 


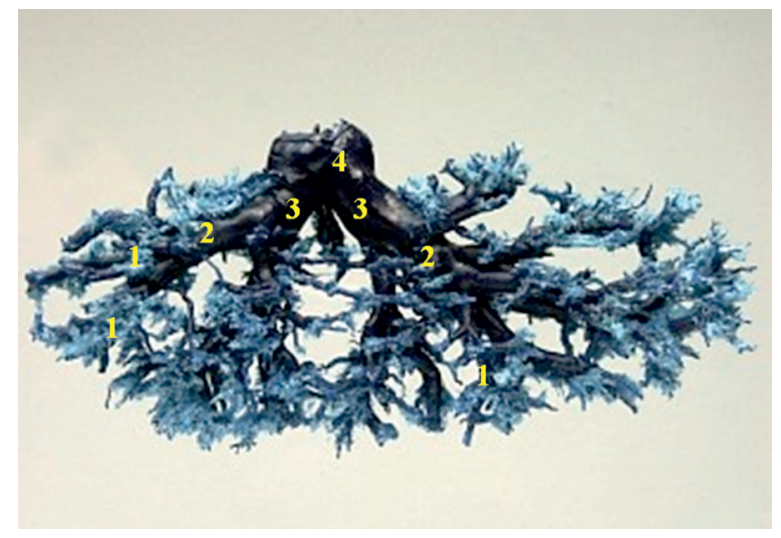

Figure 1. Types of intermediate veins; 1 - interlobar veins; 2 - primary intermediate veins of type $\mathrm{B} ; 3$ - secondary intermediate veins 4 - renal vein. Corrosion cast, Plastogen $\mathrm{G}^{\circledR}$; reduction about $1.5 \times$.

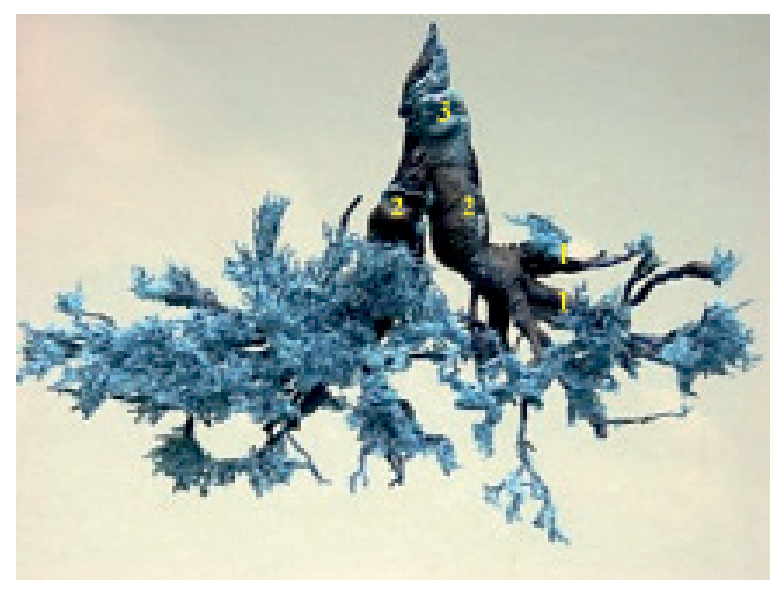

Figure 2. Types of intermediate veins; 1 - interlobar veins; 2 primary intermediate veins of type $A ; 3-$ renal vein. Corrosion cast; Plastogen $\mathrm{G}^{\circledR}$; reduction about $1.5 \times$.

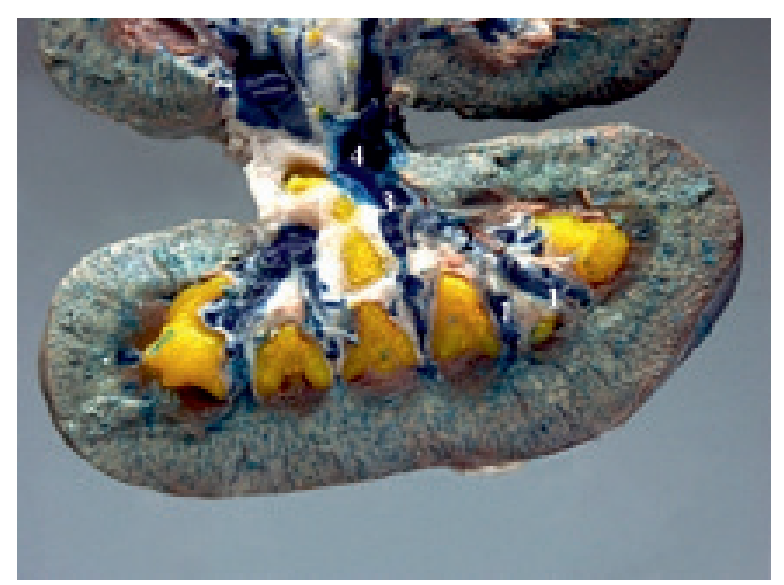

Figure 3. Intermediate veins in the kidney cross-section; 1 interlobar vein; 2 - primary intermediate vein; 3 - secondary intermediate vein; 4 - renal vein. Anatomical section with veins injected with Plastogen $\mathrm{G}^{\circledR}$ and the pelvicalyceal collecting system; reduction about $1.5 \times$.

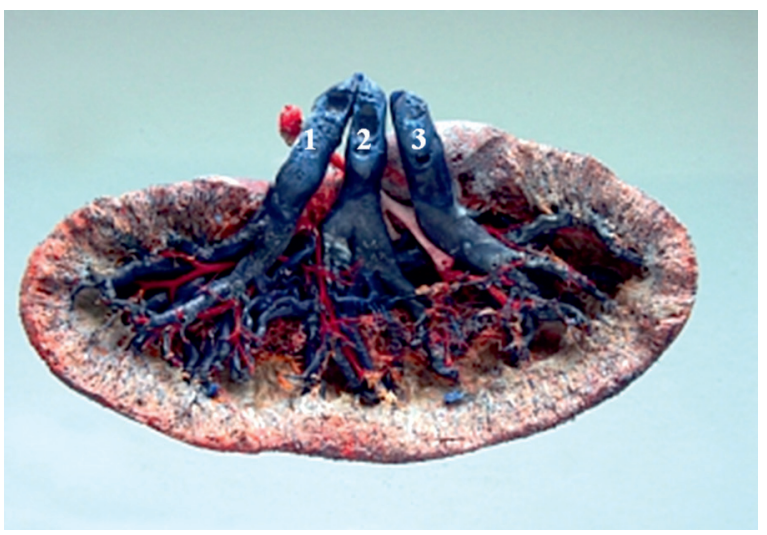

Figure 4. Intermediate veins belonging to the middle or polar group; 1 - polar intermediate vein (caudal); 2 - middle intermediate vein; 3 - polar intermediate vein (cranial). Corrosion cast; Plastogen $\mathrm{G}^{\circledR}$; reduction about $1.5 \times$.

mined kidneys (48.94\% of cases) such veins were not observed. The number of secondary IVs ranges $0-3$ vessels and again in as many as 46 kidneys (48.94\% of cases) such veins were not observed. In the kidneys, in which there are no secondary IVs, the renal vein (v. renalis) is formed as a result of joining only primary IVs of type $A$. The number of primary IVs inserted in renal veins (type $A$ ) ranges $0-4$ vessels.

The IVs run from the cranial and caudal poles of the kidney towards its hilus. In many cases, an IV located between two polar IVs can be observed (Fig. 4). The majority of IVs are located ventrally to the renal pelvis (Fig. 5). The exceptions are primary IVs inserted in secondary IVs (type B). They can be located dorsally to the so-called pelvicalyceal collecting system (Fig. 6). Intermediate veins, located between two polar IVs, come out of the renal parenchyma and run towards the renal sinus, parallelly to minor calices. The polar IVs run along cranial and caudal poles of the kidney. They come out of the renal parenchyma and run close to the ventral or dorsal wall of minor calices. After they reach the renal pelvis they change their direction and go towards its ventral side. Usually only two polar IVs collect blood from anterior and posterior venous plexuses of the pole, as well as from the central part of the kidney. Next, they join and finally form the main venous trunk. In the kidneys which have more IVs, polar vessels have a bigger diameter than those located between them. Central IVs located between polar IVs run ventrally to the renal pelvis and form the main tributary trunk of the renal vein. Polar IVs pass renal calices and they are inserted in the located centrally IVs or in the renal vein. 


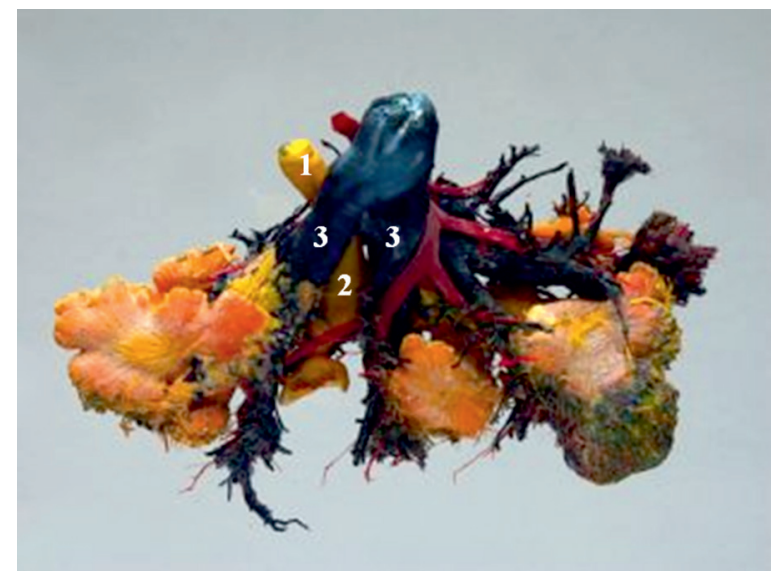

Figure 5. Intermediate veins located on the ventral side with relation to the extension of renal pelvis into the ureter (ventral side); 1 - ureter; 2 - renal pelvis; 3 - intermediate veins joining into renal vein. Corrosion cast; Plastogen $\mathrm{G}^{\circledR}$; reduction about $1.5 \times$.

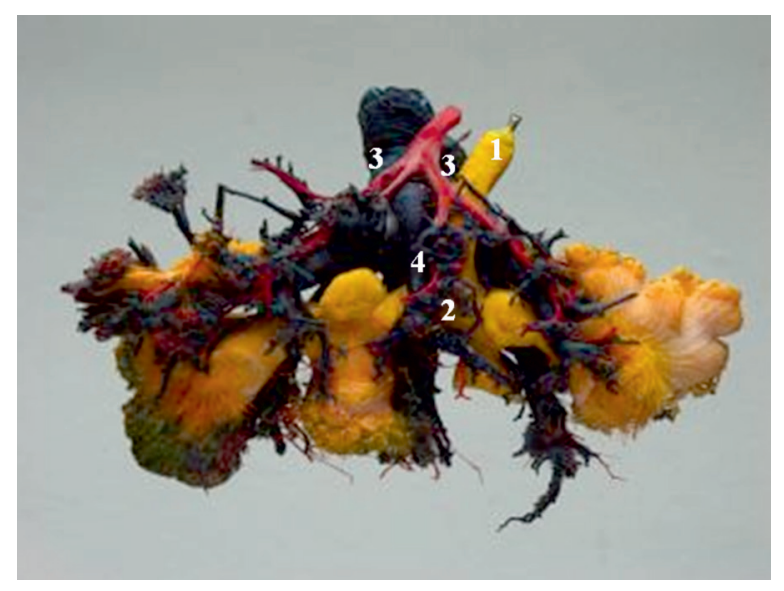

Figure 6. Intermediate veins located on the dorsal side with relation to the extension of renal pelvis into the ureter (dorsal side); 1 - ureter; 2 - renal pelvis; 3 - intermediate veins joining into renal vein; 4 - primary intermediate vein of type $B$. Corrosion cast; Plastogen $\mathrm{G}^{\circledR}$; reduction about $1.5 \times$.

The number of IVs, which directly join and form the renal vein can be different. The veins have different diameters and run in the horizontal plane of body. The size of the veins is described further in this article. In the research, 2 trunks forming the renal vein were observed (cranial and caudal one, i.e. primary and secondary IVs) in 71 cases, 3 trunks in 21 cases and only 4 in 2 cases.

In the study of IVs, secondary IVs were observed to have the biggest lumen diameter, from 3.95 to $13.4 \mathrm{~mm}$ (on average $7.96 \mathrm{~mm}$ ). Particular types of primary IVs have a smaller diameter; with regard to the veins inserted in the renal vein the diameter varied $2.45-14.75 \mathrm{~mm}$ (on average $6.7 \mathrm{~mm}$ ), as for the veins inserted in the secondary IV, the diameter varied 2.3-9.6 $\mathrm{mm}$ (on average $4.75 \mathrm{~mm}$ ).

In a swine, primary IVs directly inserted in the renal vein are the longest intrarenal vessels. Their length ranges 6.6-44 $\mathrm{mm}$ (on average $21.91 \mathrm{~mm}$ ). Secondary IVs are shorter — from 7.4 to $39 \mathrm{~mm}$ (on average $19.83 \mathrm{~mm}$ ). The shortest are primary IVs inserted in secondary IVs. Their length ranges 4.85-33.6 mm (on average $12.91 \mathrm{~mm}$ ).

\section{Statistical analysis}

The U Mann-Whitney test was used for statistical analysis. It can be concluded, that there are no statistically significant differences between the length of the primary IVs of A type and secondary IVs, both being direct tributaries of the renal vein. Statistically significant differences between these vessels appear when we compare their diameters. The average diameter of secondary IVs is greater than that of the primary IVs of type A. These differences are related to the fact that the secondary IVs are formed as a result of anastomosis of the primary IVs of type $B$ - it affects their greater diameter compared to the primary IVs of type $A$.

With regard to IVs, the highest mean cross-section areas value $\left(S=\pi r^{2}\right)$ are observed in secondary IVs - $53.04 \mathrm{~mm}^{2}$, primary IVs of type A - 38,49 $\mathrm{mm}^{2}$ and primary IVs of type $B-19.39 \mathrm{~mm}^{2}$.

The site of the origin of the vein is important for the length of IVs. If the renal vein is formed outside the kidney, IVs which the renal vein is composed of will be on average $16.2 \mathrm{~mm}$ longer than in the case when the renal vein originates in the renal sinus.

\section{DISCUSSION}

When comparing the general venous systems in a swine and a human, it can be concluded that these two systems are very similar. In both the species, like in other animals, vessels run towards the hilus. Some differences can be noticed only during a more careful examination. The differences refer to the length and diameter of the veins; sometimes to their anastomoses or their course.

The IVs mentioned by Piasecki et al. [12] are formed from venous plexuses located close to renal papillae. A similar situation can be observed in a swine kidney. They make up a sort of an extension of interlobar veins. They join and form the renal vein. 
The IVs forming the renal vein are between 14 and $46 \mathrm{~mm}$ long and, according to Kosiński [5], their diameter is between 2 and $9 \mathrm{~mm}$ or, to Piasecki et al. [12], their diameter is between 2 and $4 \mathrm{~mm}$. In a swine kidney, IVs which formed the renal vein had the following dimensions: the length from 6.6 to $44 \mathrm{~mm}$, the diameter from 3 to $14.75 \mathrm{~mm}$. The above results confirm the fact that animal IVs differ more in size than human veins. Piasecki et al. [12] mentions IVs located superiorly, inferiorly, as well as anteriorly. A similar course of IVs can be observed in a swine. They are polar, as well as central IVs located ventrally. The reason for such an arrangement is the renal pelvis which, in a human, is located posteriorly in comparison to these vessels, whereas in a swine it is found dorsally. Piasecki et al. [12] also claims that anterior IVs have a bigger diameter than polar veins. With regard to a swine the situation is different. The diameter of central IVs is smaller than this of polar IVs. An arrangement or location of particular IVs does not affect the diameter of these vessels. What is important is the fact whether they are primary or secondary IVs. Of swine intrarenal veins, the secondary IVs have the largest diameter. Piasecki et al. [12] also classified veins as primary or secondary and this classification can be applied to swine kidneys. The primary IVs are those which join and form the secondary IVs - direct tributaries of the renal vein. In the analysed material, the secondary IVs, formed as a result of joining the primary IVs, were observed in more than $50 \%$ of the studied kidneys. Vodenicharov and Gulubova [25] confirm that every main tributary of the renal vein (vena renalis cranialis, intermedia, caudalis) is formed as a result of joining vessels, which have a smaller diameter. The authors call the vessels prelobar veins. They can be compared to the primary IVs inserted in the secondary IVs (type B), described in this research. Both the prelobar veins and primary IVs inserted in secondary IVs are located on the dorsal or ventral surface of the renal pelvis. Piasecki et al. [12] states, that polar IVs and anterior IVs join and form the renal vein. Very often polar IVs are inserted in the renal vein, already formed with anterior IVs. A similar situation can be observed in a swine.

Many authors $[5,7,12,13,17,20,23]$, while examining human kidneys, counted a number of tributaries the renal vein is composed of. Poisen and Sirang [13] mention 2 or 3 main venous vessels and Smith [23] says about 2 up to 4 vessels. Kosiński [5] observed, that renal veins are formed as a result of joining 3 up to 6 IVs. Piasecki et al. [12] noted 3 up to 5 such vessels. According to Sampaio and Aragão [17], the renal vein is formed as a result of joining from 2 up to 5 main venous trunks and most often, that is in $53.8 \%$ of cases, the renal vein is composed of 3 IVs; less frequently - of 2 ( $28.8 \%$ of cases). Satyapal [20] confirms that in a human, in the majority of cases, the renal vein is formed as a result of joining 2 venous trunks (38.6\% of cases) or from 3 up to 5 trunks ( $47.15 \%$ of cases). Mandarim-Lacerda et al. [7] observed in human 2 venous trunks in $32 \%$ of cases, 3 ones in $36 \%$ of cases and 4 in $32 \%$ of cases. In the studied material, the renal vein is formed as a result of joining 2-4 venous trunks (IVs). The most frequently it is formed as a result of joining only 2 venous trunks (75.53\% of cases), less frequently it is a result of joining 3 IVs (22.34\% of cases), the least frequently it is a result of joining 4 IVs $(2.12 \%$ of cases). Bagetti Filho et al. [1] mention 2 ( $88.53 \%$ of cases) and 3 venous trunks ( $11.47 \%$ of cases), which the swine renal vein is composed of. Similar results were obtained by Vodenicharov and Gulubova [25], who confirm the appearance of 2 venous trunks, which join and form the renal vein - cranial (v. renalis cranialis) and caudal (v. renalis caudalis) in $75 \%$ of cases. Only in $25 \%$ there is another venous trunk, an intermediate one ( $v$. renalis intermedia). The venous trunks, which Vodenicharov and Gulubova [25] refers to can be compared to the IVs presented in the studied material. Thus, it can be noted that the human renal vein is formed as a result of joining a greater number of IVs. According to the majority of authors, the human renal vein is formed as a result of joining a greater number of major venous vessels than in a swine. With regard to a human kidney, there are between 2 and 6 main tributaries, which form the renal vein, whereas in a swine only 2 up to 4 such tributaries were observed. Moreover, 3 studied materials taken from a swine kidney confirm the fact that a swine renal vein is mostly formed as a result of joining only 2 vessels.

It should be pointed out that those main tributaries, which form the renal vein run in the horizontal line. Vodenicharov and Gulubova [25] observed a similar arrangement of such vessels in a swine kidney.

Bagetti Filho et al. [1] examined swine kidneys and made similar observations. They noted, that major of tributaries of the renal vein, i.e. IVs, are located close to the ventral side of the renal pelvis. Bagetti Filho et al. [1] mentions a small percentage (3.28\% of cases) of major venous trunks, which run close to the dorsal side of the renal pelvis and which are directly inserted 
in the renal vein. In the studied material, the primary IVs inserted in the secondary IVs are the only veins, which can run close to the dorsal side of the renal pelvis. This can be related to the large size of the pelvicalyceal collecting system in a swine [24]. There are no other main vessels located on the dorsal side of the renal pelvis except for the mentioned vessels. Instead of them, there are smaller retropelvic veins and small venous anastomoses, which join adjacent IVs or IVs with interlobular veins. Bagetti Filho et al. [1] present a similar course of retropelvic veins and smaller dorsal venous vessels. The results correspond to those obtained by Sleight et al. [22]. They say that in a human, on the ventral side (which corresponds to the ventral side in a swine) there are numerous veins of a big diameter. They surround the pelvicalyceal collecting system. The dorsal side contains fewer vessels which here are smaller in size. The author confirms there is a retropelvic vein. Piasecki et al. [12] does not observe main venous trunks on the dorsal side of the human pelvicalyceal collecting system. The retropelvic vein is the only vessel, which joins IVs. Poisel and Sirang [13] noted in $61.5 \%$ of cases of the analysed human material, a venous vessel (retropelvic vein) whose diameter is smaller than major tributaries of the renal vein located on the ventral side. Sampaio and Aragão [17] presented slightly different observation, that a vessel of a bigger diameter, directly inserted in the renal vein or even in the vena cava, can appear on the dorsal side of the human pelvicalyceal collecting system ( $69.2 \%$ of cases). Hollinshead [4] notes, that veins in the renal sinus are usually located close to the ventral side of the renal pelvis, but he agrees with Merklin and Michels [8], that in $30 \%$ of cases, main venous vessels which are a tributary of the renal vein run close to the dorsal side of the renal pelvis. Sampaio [14-18] also mentions main dorsal tributaries of the renal vein in a human. In a swine all tributaries of the renal vein are located on the ventral side. These data allow the conclusion, that the renal pelvis in a swine is much more accessible than in a human. Inserting a needle into the renal pelvis from the dorsal side does not entail such a great risk of damage to a larger venous trunk as it could in a human.

\section{CONCLUSIONS}

1. Intermediate veins are formed in the area of vascular anastomoses on the level of renal papillae. They constitute the lengthening of interlobar veins.

2. Considering the formation aspect, the following veins can be distinguished: primary IVs of type $A$ and $B$, as well as secondary IVs. The primary IVs of type $B$ are the vessels formed out of the interlobar veins from, which the secondary IVs are developed - direct tributaries of the renal vein. The primary IVs of type A are developed from the interlobar veins and by merging together they form a renal vein.

3. Direct tributaries of the renal vein — secondary IVs and primary IVs of type A run only on the ventral side of the renal pelvis. From among the IVs, only the primary IVs of type A can run on the ventral side of the renal pelvis.

4. From the point of view of anatomy, IVs of swine kidneys are very similar to equivalent vessels in human kidneys as regards their run and anastomoses.

\section{REFERENCES}

1. Bagetti Filho HJS, Pereira-Sampaio MA, Favorito LA, Sampaio FJB (2008) Pig kidney: Anatomical relationships between the renal venous arrangement and the kidney collecting system. J Urol, 179: 1627-1630.

2. Bastard Vallejo JE, Raventós Busquets CX, Celma Doménech A, Rosal Fontana M, Esteve M, Morote Robles J (2008) Pig model in experimental renal transplant surgery. Actas Urol Esp, 32: 91-101.

3. Czerski A, Bujok J, Gnus J, Hazuer W, Ratajczak K, Nowak M, Janeczek M, Zawadzki W, Witkiewicz W, Rusiecka A (2013) Experimental methods of abdominal aortic aneurysm creation in swine as a large animal model. J Physiol Pharmacol, 64: 185-193.

4. Hollinshead WH (1966) Renovascular anatomy. Postgrad Med, 40: 241-246.

5. Kosiński H (1976) The veins of the kidneys. Folia Morphol, 35: 277-285.

6. Kozianka J, Kielan W, Waleczek H (2003) Barium peritonitis: a study in pigs. Adv Clin Exp Med, 12: 569-573.

7. Mandarim-Lacerda CA, Sampaio FJ, Passos MA, Dallalana EM (1983) Veines intrarénales. Etude de l'angioarchitecture segmentaire et des anastomoses intersegmentaires. J D’urologie [J Urol], 89: 341-344.

8. Merklin RJ, Michels NA (1958) The variant renal and suprarenal blood supply with data on the inferior phrenic, ureteral and gonadal arteries: a statistical analysis based on 185 dissections and review of the literature. J Int Coll Surg, 29: 41-76.

9. Lederman A, Saliture Neto FT, Ferreira R, de Figueiredo LF, Otoch JP, Aun R, da Silva ES (2014) Endovascular model of abdominal aortic aneurysm induction in swine. Vasc Med, 19: 167-174.

10. Olszewski WL (2004) Międzygatunkowe przeszczepianie tkanek narządów (ksenotransplantacji). Problemy biologiczne i techniczne. In: Rowiński W, Wałaszewski J, Pączek L eds. Transplantologia kliniczna. Wydawnictwo Lekarskie PZWL, Warszawa. 
11. Pereira-Sampaio MA, Favorito LA, Sampaio FJB (2004) Pig kidney: anatomical relationships between the intrarenal arteries and the kidney collecting system. Applied study for urological research and surgical training. J Urol, 172: 2077-2081.

12. Piasecki Z, Jugowski F, Piotrowski J (1965) Rozmieszczenie naczyń żylnych w nerce ludzkiej. Folia Morphol, 24: 1-10.

13. Poisel S, Sirang H (1972) Die Verästelungstypen der Vena renalis im Hinblick auf den venösen Blutabfluss aus dem Parenchym der Niere. Acta Anat, 83: 149-160.

14. Sampaio FJB (2000) Renal anatomy: endourologic considerations. Urol Clin North Am, 27: 585-607.

15. Sampaio FJB (1996) The dilemma of the crossing vessel at the ureteropelvic junction: Precise anatomic study. J Endourol, 10: 411-415.

16. Sampaio FJB (1998) Vascular anatomy at the ureteropelvic junction. Urol Clin North Am, 25: 251-258.

17. Sampaio FJB, Aragão AHM (1990) Anatomical relationship between the renal venous arrangement and the kidney collecting system. J Urol, 144: 1089-1093.
18. Sampaio FJB, Favorito LA (1993) Ureteropelvic junction stenosis: vascular anatomical background for endopyelotomy. J Urol, 150: 1787-1791.

19. Sampaio FJB, Pereira-Sampaio MA, Favorito LA (1998) The pig kidney as an endourologic model. Anatomic contribution. J Endourol, 12: 45-50.

20. Satyapal KS (1995) Classification of the drainage patterns of the renal veins. J Anat, 186 (Part 2): 329-333.

21. Skuciński J, Nowak W, Wieczorek J, Solecki R (2007) Use of kidney transgenic pigs to allogenic and xenogenic transplantation. Med Weter, 63: 941-945.

22. Sleight MW, Gower RL, Wickham JEA (1980) Intrarenal access. Urology, 15: 475-477.

23. Smith GT (1963) The renal vascular patterns in man. J Urol, 89: 275-288.

24. Szymański J, Konarska S, Polguj M, Oszukowski P (2012) Pelvi-caliceal collecting system in swine: authors own anatomical classification. Adv Clin Exp Med, 21: 27-33.

25. Vodenicharov A, Gulubova M (1995) Renal venous architectonics in domestic swine. Anat Histol Embryol, 24: 149-153. 